\title{
Intensitas Estrus Sapi Bali yang Mengalami Silent Heat
}

\section{(THE INTENSITY OF ESTRUS OF SILENT HEAT BALI CATTLE)}

\section{Putu Sudana Agustina ${ }^{1 *}$, Desak Nyoman Dewi Indira Laksmi², I Gusti Ngurah Bagus Trilaksana ${ }^{2}$, I Made Kota Budiasa ${ }^{2}$}

${ }^{1}$ Pusat Kesehatan Hewan Sobangan, Desa Sobangan, Mengwi, Kabupaten Badung, Bali ${ }^{2}$ Laboratorium Reproduksi Veteriner Fakultas Kedokteran Hewan Universitas Udayana, Jl. PB Sudirman, Denpasar, Bali.*Email: sudana.agustina@gmail.com

\begin{abstract}
Abstrak
Penelitian ini dilakukan untuk mengetahui diameter folikel dan intensitas estrus pada sapi bali yang mengalami silent heat di kelompok ternak Sistem Pertanian Terpadu (SIPADU) di Kecamatan Mengwi Kabupaten Badung Provinsi Bali yang laksanakan pada bulan September - Oktober 2019. Sapi bali dikelompokan menjadi 2 (dua) kelompok yaitu yang mengalami silent heat dan yang mengalami estrus. Hasil penelitian menunjukkan rata - rata intensitas estrus kelompok sapi bali yang mengalami silent heat menunjukkan perbedaan yang bermakna $(\mathrm{p}<0,05)$ yaitu suhu vulva $\left(37,68 \pm 0,32^{\circ} \mathrm{C}\right)$, diameter vulva $(27,64 \pm 4,28 \mathrm{~mm})$, warna vulva (merah jambu, pembuluh perifer tidak terlihat) dan lendir vulva (tidak ada lendir sampai sedikit ada lendir), dibandingkan dengan kelompok sapi bali yang mengalami estrus yaitu suhu vulva $\left(37,96 \pm 0,51^{\circ} \mathrm{C}\right)$, diameter vulva $(31,19 \pm 5,66 \mathrm{~mm})$, warna vulva (merah terang sampai merah tua dan percabangan pembuluh perifer terlihat jelas) dan lendir vulva (kental transparan menggantung). Hasil penelitian dapat disimpulkan bahwa ada perbedaan antara itensitas estrus pada sapi bali yang mengalami silent heat dengan sapi bali yang menunjukkan estrus normal.
\end{abstract}

Kata kunci: intensitas estrus; sapi bali; silent heat

\begin{abstract}
This research was conducted to determine the follicle diameter and estrous intensity of bali cattle that ever had a silent heat in the livestock group of Integrated Farming Systems (SIPADU) in Mengwi Subdistrict Badung Regency, Bali Province, which was implemented in September - Oktober 2019. Bali cattle are grouped into 2 (two) groups; first, the Bali cattle, whichever had silent heat. Second, the Bali cattle whichever had estrous. The results showed the estrous intensity of bali cattle with silent heat showed significant differences $(\mathrm{p}<0.05)$, it is vulva temperature $\left(37,68+0,32^{\circ} \mathrm{C}\right)$, vulva diameter $(27.64+4.28 \mathrm{~mm}$ ), vulva color (pink, invisible peripheral vessels ) and vulva mucus (no mucus until there was little mucus ). Compared to the group of bali cattle which had estrus, it is vulva temperature $\left(37.96+0.51^{\circ} \mathrm{C}\right)$, vulva diameter $(31,19+5,66 \mathrm{~mm})$, vulva color (bright red to dark red and peripheral vessels branching clearly) and vulva mucus (viscous, transparent hang out). The results of the study concluded that there was a difference between the estrus intensity in bali cattle that had silent heat and bali cattle that showed true estrus.
\end{abstract}

Keywords: Bali cattle; silent heat; estrus intensity

\section{PENDAHULUAN}

Sapi bali merupakan sapi potong yang kualitas dagingnya baik, juga memiliki beberapa keunggulan, seperti tahan terhadap lingkungan yang kurang baik, mudah beradaptasi dengan lingkungan baru, persentase karkas tinggi, kandungan lemak rendah, dan sebagai ternak kerja yang baik dan efisien (Ardika et al., 2012; Besung et al., 2019; Laksmi et al., 2019). Antara dan Sweken (2012), menambahkan bahwa sapi bali memiliki kelemahan yang menjadi kendala dalam pengembangannya yakni salah satunya sering mengalami gangguan reproduksi berupa terjadinya 
birahi tenang (silent heat). Terjadinya silent heat menyebabkan peternak tidak mampu mengetahui jika ternaknya dalam keadaan birahi karena tanda birahi yang tidak jelas sehingga tidak dapat mengawinkan ternaknya pada waktu yang tepat.

Silent heat adalah suatu keadaan sapi yang tidak menunjukkan tanda estrus yang jelas namun jika dilakukan palpasi rektal teraba adanya aktifitas ovarium berupa perkembangan folikel atau perkembangan korpus luteum sebagai tanda telah terjadi ovulasi. Hal ini sering dijumpai pada hewan betina yang masih dara, induk yang berahi pertama kali post partus, hewan betina yang mendapat ransum dibawah kebutuhan normal, atau induk yang sedang menyusui anaknya atau diperah lebih dari dua kali dalam sehari (Hafez, 2000).

Follicle Stimulating Hormone (FSH) pada kejadian silent heat mampu mendorong perkembangan folikel pada ovarium sampai terjadi ovulasi, tetapi tidak mampu mendorong sel granulosa untuk mensintesa hormon estrogen yang cukup sehingga tidak mampu memunculkan tanda birahi (Pemayun, 2010). Pada sapi bali belum ada yang melaporkan atau menjelaskan perubahan alat kelamin luar pada sapi yang mengalami silent heat, sehingga penelitian ini dilakukan dengan mengukur intensitas estrus pada sapi yang mengalami silent heat.

\section{METODE PENELITIAN}

\section{Sampel Penelitian}

Penelitian ini dilakukan pada bulan September sampai Oktober 2019 di beberapa kelompok ternak Sistem Pelayanan Terpadu (SIPADU) kecamatan Mengwi, Kabupaten Badung, Bali. Materi yang digunakan adalah sapi bali betina yang telah pubertas atau estrus postpartum yang tidak menunjukkan gejala birahi yang jelas dan sapi bali yang menunjukan birahi yang jelas.

\section{Rancangan Penelitian}

Penelitian ini merupakan penelitian observasional analitik dengan rancangan
Cross Sectional Study. Untuk mengetahui adanya kejadian silent heat dilakukan pengamatan birahi sebanyak dua kali sehari yaitu pagi hari pukul 06.00-07.00 WITA dan sore hari pukul 17.00-18.00 WITA dan menggunakan pejantan pemacak.

\section{Pengamatan Estrus}

Pengamatan intensitas estrus dilakukan bersamaan dengan pengamatan silent heat untuk melihat adanya perubahan warna vulva dan vagina, adanya kebengkakan pada vulva dan perubahan suhu vagina. Pada kejadian silent heat, tanda birahi yang muncul tidak terlalu jelas sehingga pengamatan dilakukan secara teliti.

\section{Pengambilan Data Penelitian}

Penentuan skor penampilan vulva dilakukan dengan cara mengamati perubahan warna (Listiani, 2005) sebagai berikut:

Skor 1: Warna merah jambu, pembuluh perifer tidak terlihat.

Skor 2: Warna merah terang (kemerahan)dan pembuluh perifer terlihat jelas.

Skor 3: Warna merah tua dan percabangan pembuluh perifer terlihat sangat jelas.

Suhu vulva diukur menggunakan termometer digital $\left({ }^{\circ} \mathrm{C}\right)$ yang dimasukkan dalam vulva selama 3 menit saat birahi. Kebengkakan vulva diamati dengan cara pengukuran diameter menggunakan jangka sorong.

Penentuan skor sifat lendir vagina dilakukan dengan cara mengamati banyaknya lendir yang keluar dari vulva sebagai berikut:

Skor 1: tidak tampak ada lendir.

Skor 2: sedikit terlihat keluar lendir

Skor 3: lendir terlihat jelas kental tansparan menggantung.

\section{Analisis Data}

Data yang diperoleh selanjutnya ditabulasikan. Untuk data warna vulva dan lendir vulva dianalisis secara deskriptif, sedangkan untuk data diameter folikel, diameter vulva, suhu vulva dianalisis dengan Independent Sample T-test. 
Penghitungan statistik dilakukan dengan program exel 2017 for windows

\section{HASIL DAN PEMBAHASAN}

\section{Hasil}

Hasil penelitian terhadap rata-rata intensitas estrus yaitu suhu vulva, diameter vulva, warna vulva dan lendir vulva dapat dilihat pada tabel 1 .

\section{Pembahasan}

Pada penelitian (Tabel 1) ini diperoleh hasil rata - rata suhu vulva pada kelompok sapi dalam kondisi silent heat adalah 37,68 $\pm 0,32^{\circ} \mathrm{C}$, sedangkan kelompok sapi dengan kondisi estrus diketahui rata-rata suhu vulva adalah $37,96 \pm 0,51^{\circ} \mathrm{C}$. Tampak ratarata suhu vulva pada kelompok sapi dalam kondisi silent heat menunjukkan perbedaan yang bermakna dibandingkan dengan kelompok sapi dalam kondisi estrus $(\mathrm{P}<0,05)$.

Tabel 1. Rata-rata intensitas estrus pada sapi bali yang mengalami silent heat dan estrus

\begin{tabular}{clcc}
\hline \multirow{2}{*}{ No } & \multicolumn{1}{c}{ Parameter } & Silent Heat & Estrus Normal \\
\cline { 3 - 4 } & & Mean \pm SD & Mean \pm SD \\
\hline 1 & Suhu Vulva $\left({ }^{\circ} \mathrm{C}\right)$ & $37,68 \pm 0,32^{\mathrm{a}}$ & $37,96 \pm 0,51^{\mathrm{b}}$ \\
2 & Diameter Vulva $(\mathrm{mm})$ & $27,64 \pm 4,28^{\mathrm{a}}$ & $31,19 \pm 5,66^{\mathrm{b}}$ \\
3 & Warna Vulva & $1 \pm 0^{\mathrm{a}}$ & $2,40 \pm 0,5^{\mathrm{b}}$ \\
4 & Lendir Vulva & $1,40 \pm 0,50^{\mathrm{a}}$ & $3,00 \pm 0^{\mathrm{b}}$ \\
\hline
\end{tabular}

Keterangan: Nilai yang diikuti oleh superscript dengan huruf yang berbeda pada satu baris menunjukkan perbedaan yang bermakna $(\mathrm{P}<0,05)$.

Menurut Anisa et al. (2016) rata-rata suhu vulva pada sapi Simental peranakan Ongole (SimPO) adalah sebesar $38,41^{\circ} \mathrm{C}$. Purwasih et al. (2014) mengatakan bahwa tingginya kadar estrogen dalam darah akan diikuti dengan meningkatkan hormon adrenalin yang menyebabkan memicu denyut dan kontraksi jantung yang dapat meningkatkan sirkulasi darah. Meningkatnya kadar estrogen juga dapat menyebabkan meningkatnya jumlah suplai darah ke saluran alat kelamin, sehingga terjadi peningkatan aktivitas sel - sel di daerah vagina yang berakibat meningkatnya temperatur vagina (Ratri et al., 2011).

Tampak juga rata-rata diameter vulva kelompok sapi dengan kondisi estrus adalah $31,19 \pm 5,66 \mathrm{~mm}$, sedangkan pada kelompok sapi dengan silent heat ditemukan bahwa rata-rata diameter vulva adalah 27,64 \pm 4,28 $\mathrm{mm}$. Jelas bahwa diameter vulva sapi bali yang mengalami silent heat menunjukan berbeda bermakna dari diameter vulva sapi bali yang mengalami estrus $(\mathrm{P}<0,05)$. Hal ini menunjukkan bahwa pada saat suplai darah ke uterus bertambah maka menyebabkan mukosa berwarna merah jambu dan terjadi kongesti karena vaskularisasi bertambah serta pada saat estrus dan menyebabkan terjadi pembengkakan pada vulva membengkak (Hafez, 2000). Ratri et al. (2011) mengatakan bahwa hormon estrogen menyebabkan meningkatnya sirkulasi darah di daerah vagina meningkat sehingga menyebabkan warna vagina menjadi merah dan meningkatnya cairancairan pada sel-sel vagina sehingga menyebabkan vulva dan vagina membengkak.

Warna vulva kelompok sapi bali dengan kondisi silent heat adalah merah jambu, pembuluh perifer tidak terlihat. Lendir vulva pada sapi bali dengan kondisi silent heat seringkali tidak tampak ada lendir sampai sedikit ada lendir. Sedangkan warna vulva kelompok sapi dengan estrus memiliki kecenderungan merah terang sampai merah tua dan percabangan pembuluh perifer terlihat jelas dan lendir vulva ditemukan lebih banyak dan konsistensinya cenderung kental transparan dan menggantung. Hal ini 
disebabkan hormon estrogen. Semakin tinggi kadar estrogen akan memberi respon pada adenohipofisa untuk mensekeresikan hormon adrenalin oleh kelenjar adrenal sehingga memicu kerja jantung dan mensuplai darah ke pembuluh darah sehingga warna vulva menjadi merah. Meningkatnya kadar estrogen berhubungan dengan memerah dan membengkaknya vulva saat estrus yang merangsang aliran darah ke saluran reproduksi dan organ genital terkait (Saara et al., 2011). Siswati (2014) menambahkan bahwa estrogen akan meningkatkan jumlah suplai darah pada alat kelamin yang menyebabkan terjadinya pembengkakan pada vulva dan vestibulum menjadi berwarna merah terang karena terjadi kongesti pembuluh darah.

Anisa (2016) menyatakan bahwa lendir serviks yang dikeluarkan dipengaruhi oleh estrogen yang membuat hormon adrenalin dan hormon oksitosin disekresikan, hormon oksitosin akan membuat sel endotelium pembuluh darah menjadi permeabel yang meningkatkan aktivitas sel goblet sehingga terjadi penimbunan air sehingga tekanan sel goblet tinggi mengakibatkan sel goblet pecah sehingga keluar lendir serviks. Frandson et al. (2003) mengatakan Hormon estrogen merangsang penebalan dinding vagina, peningkatan vaskularisasi sehingga menyebabkan alat kelamin bagian luar mengalami pembengkakan dan berwarna kemerahan, dan peningkatan sekresi vagina yang ditandai dengan adanya lendir menggantung pada vulva atau menempel di sekitarnya.

\section{SIMPULAN DAN SARAN}

\section{Simpulan}

Hasil penelitian dapat disimpulkan bahwa diameter vulva dan suhu vulva pada sapi bali yang mengalami silent heat lebih kecil dari pada sapi bali yang estrus. Warna vulva kurang tampak jelas pada kasus sapi bali yang mengalami silent heat dibandingkan sapi bali yang estrus. Lendir vulva lebih sedikit pada kasus sapi bali yang mengalami silent heat dibandingkan sapi bali yang estrus.

\section{Saran}

Perlu adanya penelitian lebih lanjut berupa pengukuran kadar estrogen pada sapi bali yang mengalami silent heat dan tingkat keberhasilan Insminasi Buatan yang dilakukan pada sapi bali yang mengami silent heat.

\section{UCAPAN TERIMAKASIH}

Penulis mengucapkan terima kasih kepada Dekan FKH Unud, Kelpmpok ternak yang tergabung dalam Sistem Pelayanan Terpadu (SIPADU) kecamatan Mengwi, Kabupaten Badung dan semua pihak yang turut membantu dalam proses penelitian.

\section{DAFTAR PUSTAKA}

Anisa E, Ondho YS, Samsudewa D. 2017. Pengaruh body condition score (BCS) berbeda terhadap intensitas birahi sapi induk simmental peranakan ongole (SIMPO). J. Sain Peternakan Indonesia. 12(2):133-141

Antara M, Sweken P. 2012. Kelayakan usaha pembibitan sapi bali di Desa Gerokgak, Kecamatan Gerokgak Kabupaten Buleleng, Bali. Proc. Seminar Nasional Peningkatan Produksi dan Kualitas Daging Sapi Bali Nasional. Denpasar 14 September 2012. Pp. 74-105.

Ardika IN, Warmadewi DA, Artiningsih RNM. 2012. Keragaman sifat produksi sapi bali di Nusa Penida sebagai sumber bibit sapi bali murni. Proc. Seminar Nasional Peningkatan Produksi dan Kualitas Daging Sapi Bali Nasional. Denpasar 14 September 2012. Pp. 246255.

Besung INK, Watiniasih NL, Mahardika GNK, Agustina KK, Suwiti NK. 2019. Mineral levels of Bali cattle (Bos javanicus) from different types of land in Bali, Nusa Penida, and Sumbawa Islands (Indonesia). Biodiversitas. 
20(10): 2931-2936.

Diskin MG, Mackey DR, Roche JF, Sreenan JM. 2003. Effects of nutrition and metabolic status on circulating hormones and ovarian follicle development in cattle. Anim. Reprod. Sci. 78. 345-370.

Frandson RD, Wilke WL, Fails AD. 2003. Anatomy and hysiology of Farm Animal. $7^{\text {th }}$ Ed. Lippincott Williams and Wilkins. Philadelphia. Pp. 395-404.

Hafez ESE. 2000. Reproduction in farm animals. $7^{\text {th }}$ Ed. Lippincott William \& Wilkins. A Wolters Kluwer Company. Chapter 3, Pp. 33-35.

Hafizuddin, Tongku N, Siregar, Akmal M. 2012 Hormon dan peranannya dalam dinamika folikuler pada hewan domestik. Jurnal Edukasi dan Sains Biologi 1(1):21-24

Laksmi DNDI, Pemayun TGO, Damriyasa IM, Dharmawan NS. 2016. Administration of increases the of level of follicle stimulating hormone (FSH) and development of ovarium follicles in postpartum anestrus of bali cattle. Bali Med. J. 5(2): 69-73.

Laksmi DNDI, Trilaksana IGNB, Darmanta RJ, Drawan M, Bebas IW, Agustina KK. 2019. Correlation between body condition score and hormone level of Bali cattle with postpartum anestrus. Indian J. Anim. Res. 53(12): 1599-1603.

Listiani D. 2005. Pemberian PGF2 $\alpha$ pada sapi peranakan ongole yang mengalami gangguan korpus luteum persisten. Skripsi. Universitas Diponegoro. Semarang.

Noseir WMB. 2003. Ovarian follicular activity and hormonal profile during estrous cycle in cows: the development of 2 versus 3 waves. Reprod. Biol. Endocrinol. 1: 50-55.

Pemayun TGO. 2010. Kadar Progesteron Akibat Pemberian PMSG Dan GN-RH Pada Sapi Perah Yang Mengalami Anestrus Postpartum. Buletin Veteriner. 2(2): 85-91.

Purwasih R, Seiatin ET, Samsudewa D. 2014. The effect of anredera cordifolia (Ten) steenis suplementation process evluated by oestrus post prtum behavior and ferning. J. Indonesian Tropi. Anim. Agric. 9(1) :17-22.

Ratri RD, Wahyuningsih, Widayati DT. 2011. Respon estrus pada kambing peranakan ettawa dengan body condition score 2 dan 3 terhadap kombinasi implant controlled internal drug release jangka pendek dengan injeksi prostaglandin f2 alpha. $J$. Kedokteran Hewan. 5(1): 11-16.

Saara CS, Clark SG, Knox RV, Tamassia MA. 2011. Vulvar Skin temperature changes significantly during estrus in swine as determined by digital infrared thermograph. J. Swine Health Prod. 19(3): 152.

Siswati E. 2014. Tampilan Birahi Sapi Peranakan Ongole dan Sapi Simmen-tal Peranakan Ongole Berdasarkan Gambaran Ferning Serviks dan Saliva di Kecamatan Pulokulon, Kabupaten Grobogan. Skripsi. Fakultas Peternakan dan Pertanian. Universitas Diponegoro, Semarang.

Torres AM, Sanchez AG, Aguilar. 2012. Follicular development in domestic ruminants. Trop. Subtrop. Agroecosystems. 15(1): S147-S160. 